\title{
Answer to the Letter to the Editor of A. Goel concerning "Clival screw and plate fixation by the transoral approach for the craniovertebral junction: a CT-based feasibility study" by Lin J, Kong G, Xu X, Liu Q, Huang Z, Zhu Q, and Ji W (Eur Spine J. 2019; doi:10.1007/ s00586-019-06039-5)
}

Wei Ji ${ }^{1} \cdot$ Qingan Zhu ${ }^{1} \cdot J$. Lin $^{1}$

Received: 2 September 2019 / Accepted: 3 September 2019 / Published online: 9 September 2019

(c) Springer-Verlag GmbH Germany, part of Springer Nature 2019

Dear Editor,

We appreciate the letter from Prof. A. Goel, whose team had reported a patient with congenital basilar invagination after odontoidectomy in the year 1994, and the stability reconstruction was performed by a double compression stainless steel radio-ulnar fixation plate with screws place to the clivus and the body of the cervical vertebra [1]. For the anterior occipitocervical reconstruction, except for the above fixation method, the modified titanium mesh was also applied [2]. However, for the clival screw fixation, the anatomy of the clivus was unclear; furthermore, there was no specific instrumentation for the craniovertebral region anteriorly. Then, we conducted series anatomic studies for the clival screw placement [3]. Based on those anatomic data, a novel clivus plate fixation system specific to craniovertebral region was developed, which was biomechanically prior to the conventional fixation techniques [4]. Therefore, there are innovations in our series of works as stated above, and that will lay a foundation for the clinical application. Surely, in our previous studies, the researches of Dr. Goel's team and studies related to the method of the modified titanium mesh were also quoted.

\section{References}

1. Goel A, Laheri VK (1994) Plate and screw fixation for atlantoaxial dislocation. (Technical report). Acta Neurochir 129:47-53

2. Suchomel P, Buchvald P, Barsa P, Froehlich R, Choutka O, Krejzar Z, Sourkova P, Endrych L, Dzan L (2007) Single-stage total $\mathrm{C}$-2 intralesional spondylectomy for chordoma with three-column reconstruction. Technical note. J Neurosurg Spine 6(6):611-618

3. Ji W, Wang XY, Xu HZ, Yang XD, Chi YL, Yang JS, Yan SF, Zheng JW, Chen ZX (2012) The anatomic study of clival screw fixation for the craniovertebral region. Eur Spine J 21:1483-1491

4. Ji W, Tong J, Huang Z, Zheng M, Wu X, Chen J, Zhu Q (2015) A clivus plate fixation for reconstruction of ventral defect of the craniovertebral junction: a novel fixation device for craniovertebral instability. Eur Spine J 24:1658-1665

Publisher's Note Springer Nature remains neutral with regard to jurisdictional claims in published maps and institutional affiliations.

Wei Ji

spineji@126.com

$\checkmark$ Qingan Zhu

qinganzhu@gmail.com

1 Department of Spinal Surgery, Nanfang Hospital, Southern Medical University, Guangzhou, China 